\title{
Globular-to-Spray Transition in Cold Wire Gas Metal Arc Welding
}

\author{
CW-GMAW transitions faster to a spray transfer regime
}

BY R. A. RIBEIRO, P. D. C. ASSUNÇÃO, E. B. F. DOS SANTOS, E. M. BRAGA, AND A. P. GERLICH

\begin{abstract}
The electrical current required for a transition from globular to spray droplet transfer during gas metal arc welding (GMAW) is determined by the specified wire feed speed in the case of constant-voltage power supplies. Generally, in narrow groove welding, spray transfer is avoided, because this transfer mode can severely erode the groove sidewalls. This work compared the globular-to-spray transition mechanism in cold wire gas metal arc welding (CWGMAW) vs. standard GMAW. Synchronized high-speed imaging with current and voltage samplings were used to characterize the arc dynamics for different cold wire mass feed rates. Subsequently, the droplet frequency and diameter were estimated, and the parameters for a globular-to-spray transition were assessed. The results suggest that the transition to spray occurs in CW-GMAW at a lower current than in the standard GMAW process. The reason for this difference appears to be linked to an enhanced magnetic pinch force, which is mainly responsible for metal transfer in higher welding current conditions.
\end{abstract}

\section{KEYWORDS}

- Gas Metal Arc Welding (GMAW) • Cold Wire Gas Metal Arc Welding (CW-GMAW) • Globular-to-Spray Transition - Transition Current • Metal Vapor Production • Thermal Balance

\section{Introduction}

Understanding the phenomena controlling metal transfer in gas metal arc welding (GMAW) is fundamental to identifying the correct specifications and process parameters used in a welding procedure. The use of incorrect parameters may impair the quality and reliability of welds in service.

While studying metal transfer, a key parameter is the critical arc current at which globular transfer transitions to spray transfer. Presently, this is poorly understood due to the complexity of the underlying physics. For instance, Lowke (Ref. 1) proposed an equation to calculate the transition current, but this model is only applicable to welding using $100 \%$ argon shielding gas, while a wide range of welding applications use mixed gases or $\mathrm{CO}_{2}$ shielding.

Moreover, the model only takes into account the steel wire diameter, the surface tension of the molten metal, and the magnetic permeability of free space. Lowke (Ref. 2) subsequently extended the equation to aluminum and copper electrodes. Methong et al. (Ref. 3 ) reported that during the transition in a binary shielding gas (argon and carbon dioxide), the metal vapor concentrates toward the edges of the arc as the welding current increases.

Ribeiro et al. (Ref. 4) reported that in cold wire gas metal arc welding (CW-GMAW), the increase of the cold wire feed rate leads to a significant increase in current compared to the standard GMAW when in spray transfer mode. Moreover, Ribeiro et al. (Ref. 5) reported CW-GMAW operating in spray transfer can be used for narrow groove welding (NGW) with no sidewall erosion, because the arc is pinned preferentially to the cold wire.

The CW-GMAW process involves an increase in current when the cold wire feed rate increases. However, unlike GMAW, when this occurs the area of the heat-affected zone (HAZ) decreases. It is worthwhile to study the influence of this phenomenon on the globular-to-spray transition to clarify how metal transfer mechanisms differ from conventional GMAW before it can be used in practical applications. This work seeks to identify the conditions under which CW-GMAW transitions to spray transfer in comparison to GMAW using the same welding parameters.

\section{Methodology}

Bead-on-plate welds were deposited on AISI 1020 plain carbon steel with a thickness of $6.35 \mathrm{~mm}(1 / 4 \mathrm{in}$.) using a Lincoln Electric Power Wave ${ }^{\circledR}$ R500 power source operating in 


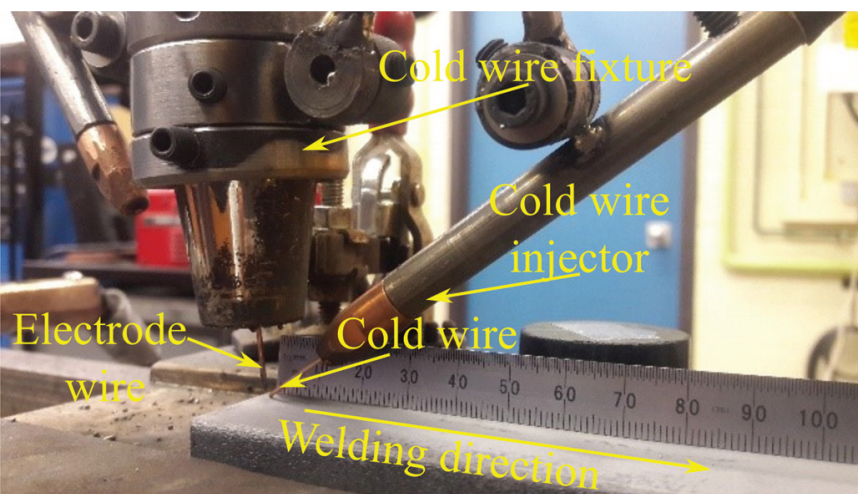

Fig. 1-General setup for welding experiments.

constant voltage (CV). ER70S-6 was used as electrode wire and cold wire, with nominal diameters of $1.2 \mathrm{~mm}$ (0.045 in.) and $0.9 \mathrm{~mm}(0.035 \mathrm{in}$.$) , respectively. Table 1$ presents the nominal chemical composition of the welding wire and the base metal. The shielding gas mixture used for all welds was Ar- $15 \% \mathrm{CO}_{2}$ at the flow of $40 \mathrm{ft}^{3} / \mathrm{h}(19 \mathrm{~L} / \mathrm{h})$.

The equipment and gun layout for welding is presented in Fig. 1, where the cold wire feed position can be seen as relative to the electrode wire and the device used to feed the auxiliary wire. During welding, the current and voltage were recorded at a frequency of $10 \mathrm{kHz}$ for $2 \mathrm{~s}$ to assess the electric properties of the arc in-situ. Moreover, synchronized high-speed imaging was used to monitor the dynamic behavior of the arc at 5000 frames/s for $2 \mathrm{~s}$ with a shutter speed of $25 \mu$ s, while a $900 \mathrm{~nm} \pm 10 \mathrm{~nm}$ filter was used to visualize the arc. To determine the welding parameters used in this study, preliminary welds were performed to identify parameters that caused metal transfer to be fully globular and fully spray. Hence, the transition current range from globu-

Table 1-Nominal Composition of the Welding Wire and Base Metal

\begin{tabular}{cccccccc} 
Material & \multicolumn{8}{c}{ Nominal Chemical Composition (wt-\%) } \\
& C & Si & Mn & P & S & Cr & Fe \\
AISI 1020 & 0.18 & - & 0.30 & - & Max. 0.005 & - & Bal. \\
ER70S-6 & 0.15 & 1.15 & 1.85 & 0.025 & 0.035 & 0.05 & Bal.
\end{tabular}

lar-to-spray was identified for standard GMAW.

Subsequently, a cold wire feed was introduced to determine if the globular-to-spray transition occurred at a different arc current in CW-GMAW. Table 2 presents the welding parameters used to determine the range of globular-to-spray transition that occurs in standard GMAW along with their response in current and voltage. It was found the range for the transition current for GMAW is 265 to $293 \mathrm{~A}$.

After determining the globular-to-spray transition parameters, the same parameters were used to carry out the CW-GMA welding using cold wire feed rates of 20,80 , and $140 \%$. These feed rates refer to mass feed rate in units of $\mathrm{kg} / \mathrm{s}$ as a fraction of the welding electrode wire mass rate. For all the cold-wireassisted welds, the contact to work distance (CTWD) was kept the same $(17 \mathrm{~mm})$.

The images obtained using a $900 \mathrm{~nm}$ filter were manually processed to measure the droplet detachment frequency $(\mathrm{Hz})$. However, prior to the manual measurement of droplets, the fast Fourier transform (FFT) of the voltage signal was performed to estimate the droplet frequency. Due to a $2-12 \%$ margin of error between the manually counted and FFT estimated droplet frequency, the reported droplet frequency in this work refers to the manually counted value. Moreover, the FFT determined value of frequency cannot be statistically treated to provide the mean and variation range, because it is only one value of frequency. The droplet diameter was estimated from the detachment frequency. The droplet frequency was counted in five intervals of $0.36 \mathrm{~s}$ each, summing in total $1.8 \mathrm{~s}$ of the total $2 \mathrm{~s}$ sampled during welds. The values presented are thus the average of five measurements, which consider approximately the whole sampled time, and the error bars represent a 95\% confidence interval.

Based on the droplet diameter measurements, the transition from globular to spray could be identified based on when the droplet was smaller than the nominal electrode diameter (which was $1.2 \mathrm{~mm}$ in the present work). Table 3 presents the welding parameters for cold wire welds and the current and voltage machine response after welding. The droplet diameter was calculated from the measured values of drop detachment frequency (Ref. 6):

$$
d=\left(W F S \times d_{e}^{2} / 40 \times f_{d}\right)^{1 / 3}
$$

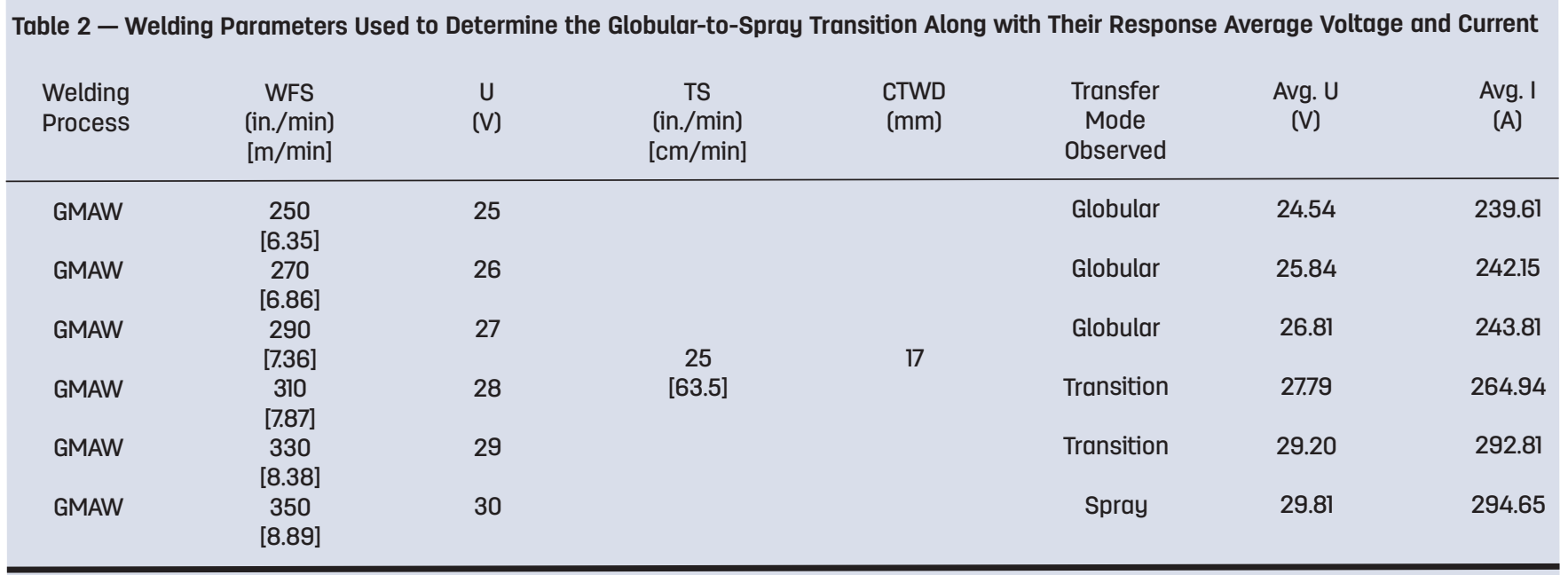



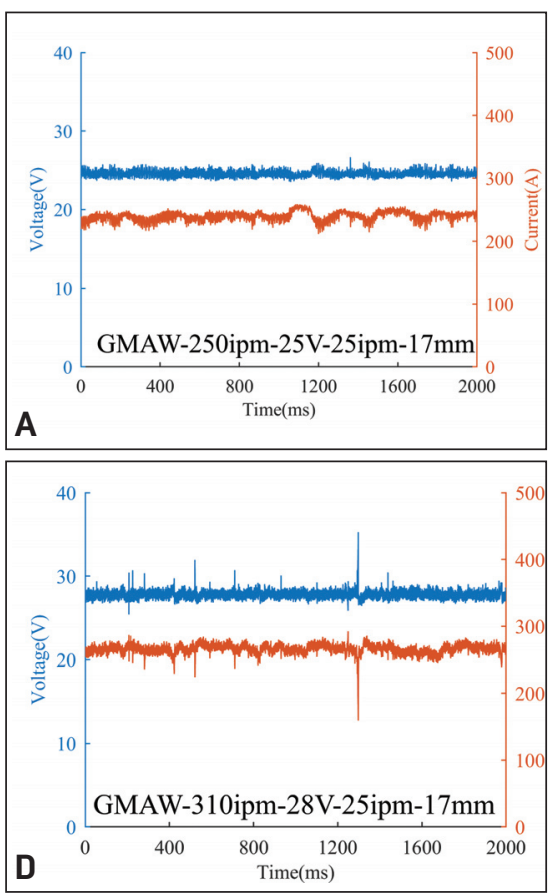
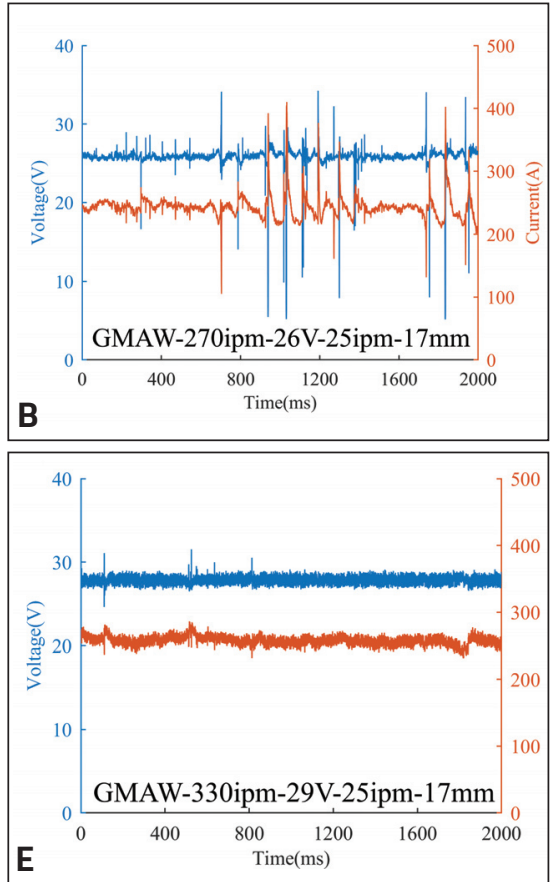
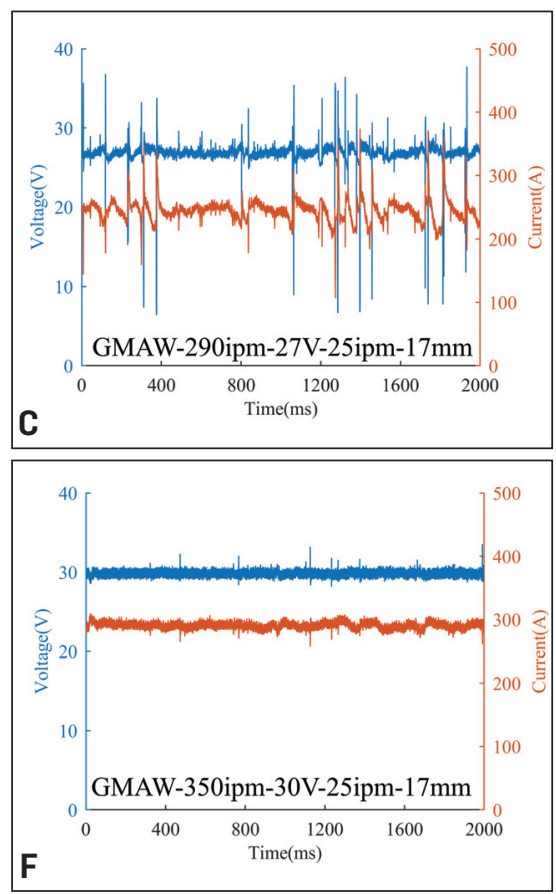

Fig. 2 - Oscillograms for standard GMAW conditions: A - 250 in./min; B - $270 \mathrm{in./min;} \mathrm{C-290} \mathrm{in./min;} \mathrm{D} \mathrm{-} 310$ in./min; E - 330 in./min; F- 350 in./min. Plot for the entire sampling.

where $d$ is the droplet diameter, WFS is the wire feed speed, $d_{e}$ is the diameter of the wire electrode, and $f_{d}$ is droplet frequency.

The instantaneous arc resistance $\left(R_{i}\right)$ was estimated using the values of the instantaneous voltage $\left(U_{i}\right)$ and instantaneous current $\left(I_{i}\right)$ according to the following:

$$
R_{i}=U_{i} / I_{i}
$$

The values of $R_{i}$ were averaged over the sampled period of $2 \mathrm{~s}$ and presented in the average resistance of the arc plasma section.

\section{Results}

\section{Metal Transfer Dynamics}

Figure 2 shows the oscillograms for the standard GMAW conditions used to identify the transition zone between globu- lar and spray modes. High-speed images are shown only at the transition, which occurred between 310 and $350 \mathrm{in.} / \mathrm{min}$, and the spray condition at a wire feed speed of $350 \mathrm{in} . / \mathrm{min}$.

Figure 3 shows representative high-speed images of the two conditions in which globular-to-spray transition occurs, namely Fig. 3A and B; and the fully spray condition is shown in Fig. 3C. As noted, the criterion adopted to distinguish between those was based on whether the droplet diameter is larger than the electrode diameter, corresponding to globular transfer. A droplet diameter lower than the electrode diameter indicates spray transfer mode. However, during transition the droplet size may fluctuate lower or higher than the electrode diameter.

The conditions shown in Fig. $2 \mathrm{~B}$ and $\mathrm{C}$ transition from globular transfer mode to short circuit, which Scotti et al. (Ref. 7) described as interchangeable metal transfer (ITM). This can be ascribed to the following: 1) a variation in specific resistivity of the arc column, and 2) a higher post short-circuit current. These two features in ITM come from a higher increase in wire feed speed compared to a small increase in voltage, as can be

\begin{tabular}{|c|c|c|c|c|c|c|c|}
\hline $\begin{array}{l}\text { Welding } \\
\text { Process }\end{array}$ & $\begin{array}{c}\text { WFS } \\
\text { (in./min) } \\
\text { [m/min] }\end{array}$ & $\begin{array}{c}\text { CW } \\
\text { Percent } \\
(\%)\end{array}$ & $\begin{array}{c}\text { U } \\
\text { (V) }\end{array}$ & $\begin{array}{c}\text { TS } \\
\text { (in./min) } \\
\text { [cm/min] }\end{array}$ & $\begin{array}{l}\text { CTWD } \\
(\mathrm{mm})\end{array}$ & $\begin{array}{l}\text { Avg. U } \\
\text { (V) }\end{array}$ & $\begin{array}{l}\text { Avg. I } \\
\text { (A) }\end{array}$ \\
\hline \multirow{4}{*}{ CW-GMAW } & 310 & 20 & & & & 28.12 & 270.28 \\
\hline & [7.87] & 80 & 28 & & & 28.12 & 274.42 \\
\hline & 330 & 80 & 29 & & & 29.14 & 283.01 \\
\hline & [8.89] & 140 & & & & 29.14 & 299.07 \\
\hline
\end{tabular}




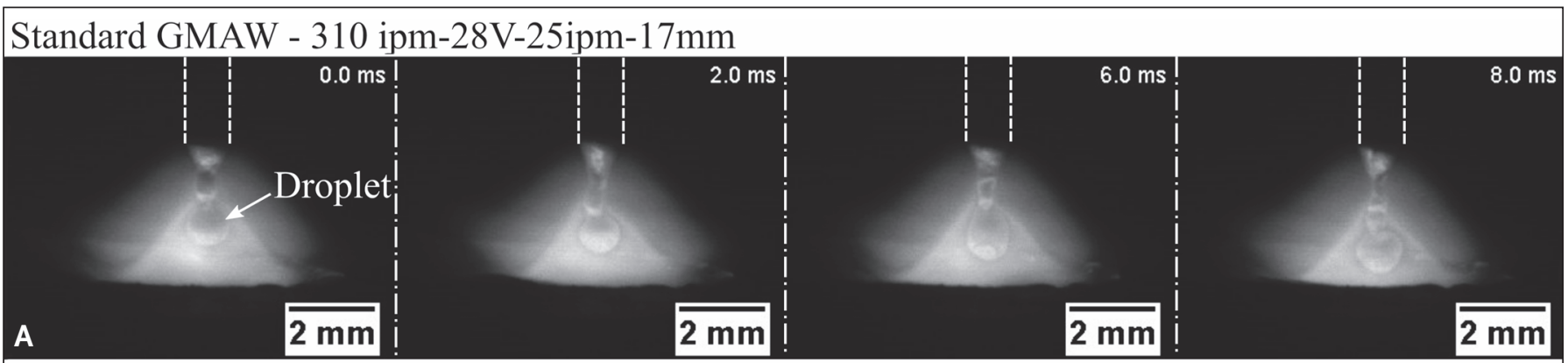

Standard GMAW - 330 ipm-29V-25ipm-17mm

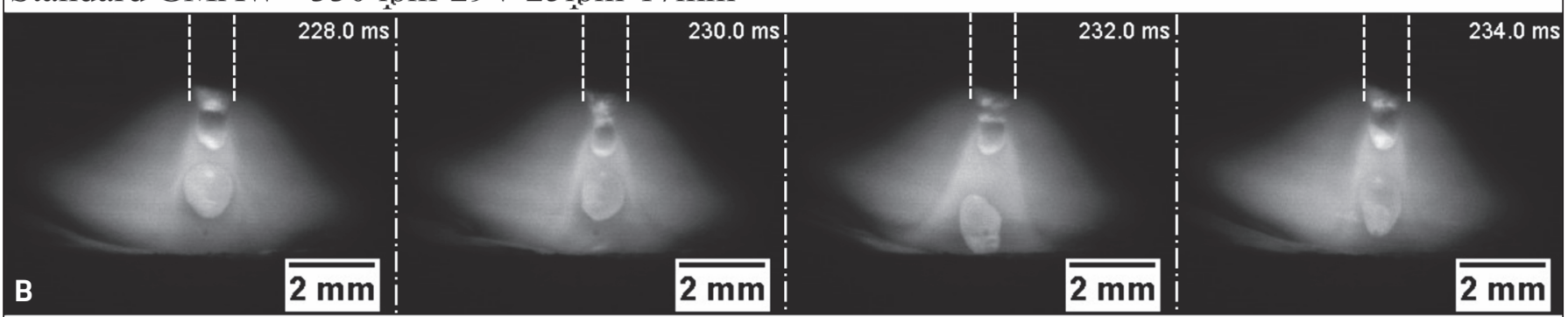

Standard GMAW - 350 ipm-30V-25ipm-17mm

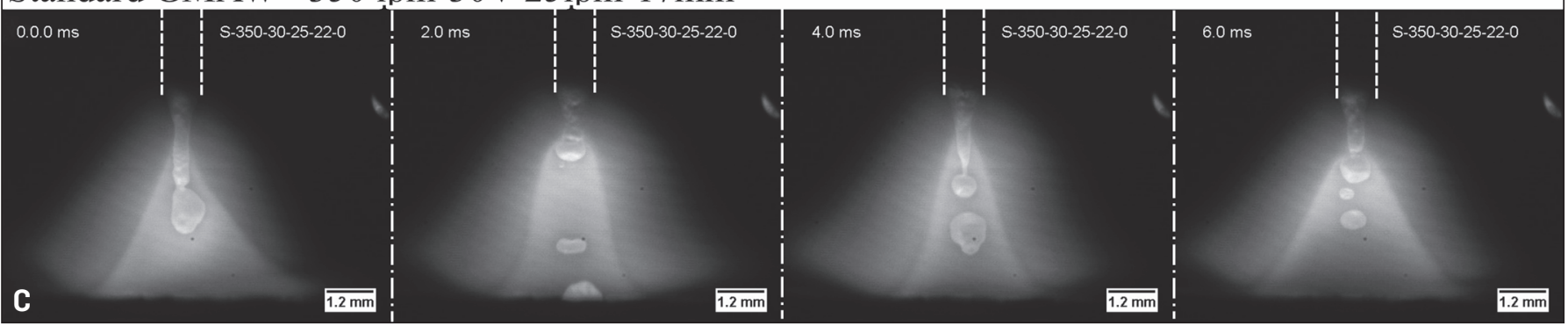

Fig. 3-A, B - High-speed images of transition from globular to spray; $C$ - the fully spray condition.

noted from the welding parameters in this study. As soon as the energy in the arc is sufficient to sustain a spray transfer, then interchangeable transfer ceases.

The spray transfer current in standard GMAW is, on average, 294.7 A (as reported in Table 2). Figure 4 shows the highspeed images of the welds in the transition region with cold wire feed. The droplet size was close to the wire diameter when $20 \%$ cold wire feed rate was used - Fig. 4 A. When $80 \%$ cold wire feed rate was used, there was an instantaneous decrease in droplet diameter, showing the transition from globular to spray began at this cold wire feed rate - Fig. 4B. Further increasing the cold wire feed rate led to a full axial spray transfer mode with droplets smaller than the wire diameter. In fact, the current applied for the spray regime condition is, on average, 275.4 A, which is smaller than the current for fully spray transfer for standard GMAW using the same wire feed speed and voltage.

It is also interesting to note that when the cold wire was introduced at a feed rate of $20 \%$, there was an instability of voltage and current signals, which are reflected in the current oscillation in Fig. 5A. When the cold wire feed was increased to $80 \%$, that led to a stabilization of the current and voltage signals, as shown in Fig. 5B. However, at a cold wire feed rate of $140 \%$, an instability in the voltage and current signal was caused by the injection of more cold wire than could be accom- modated by the arc. This caused part of the cold wire to emerge out of the pool and disturb the arc - Figs. $4 \mathrm{C}$ and $5 \mathrm{C}$. In Fig. 5C, this disturbance was a short circuit caused by the cold wire tip; when this happened, the voltage decreased to levels below $10 \mathrm{~V}$.

Figure 6 shows the high-speed images for the CW-GMAW welds using a feed rate of $330 \mathrm{in} . / \mathrm{min}$. Figure $6 \mathrm{~A}$ shows that when $20 \%$ cold wire feed was introduced, the droplet diameter was about the size of the wire diameter, causing behavior similar to that shown in Fig. 5 . When $80 \%$ cold wire was introduced in the arc, the droplet diameter started to decrease to levels lower than the electrode diameter. Again, for this particular feed rate, there was a stabilization of the arc phenomena, which reflected the stabilization of the measured signals of voltage and current. The arc position regarding the cold wire was intermediate; the arc was not completely pinned to the secondary wire as reported by Ribeiro et al. (Ref. 4).

Further increasing the cold wire led to instabilities due to insufficient energy levels in the arc to sustain the extra wire, as observed in Fig. 5C. At the cold wire fraction (140\%), part of the cold wire again emerged out the pool. The cold wire emerging out of the pool can short circuit the arc (refer to Fig. 7C), briefly causing the values of voltage to drop to levels below 10 $\mathrm{V}$. It can be seen that the arc was completely attached to the cold wire. 


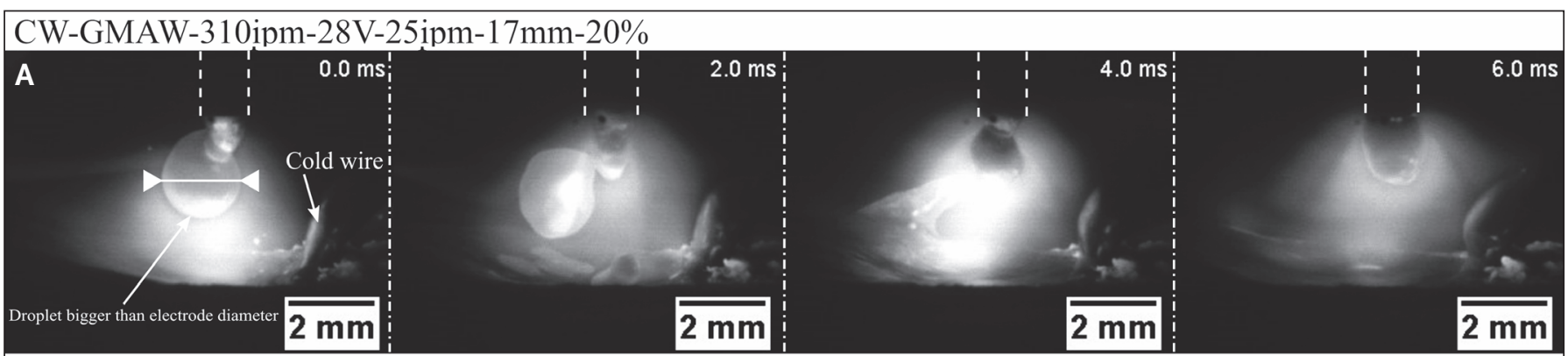

CW-GMAW-310ipm-28V-25ipm-17mm-80\%

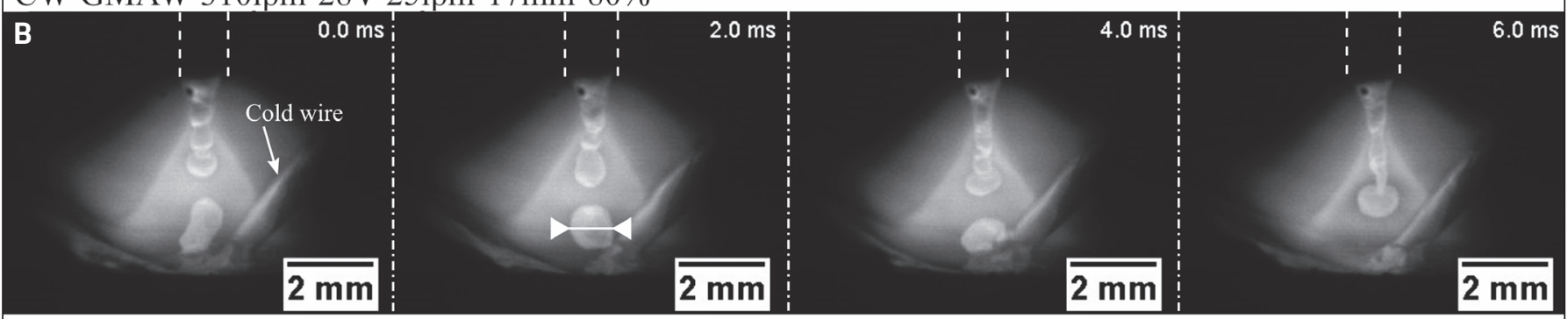

CW-GMAW-310ipm-28V-25ipm-17mm-140\%

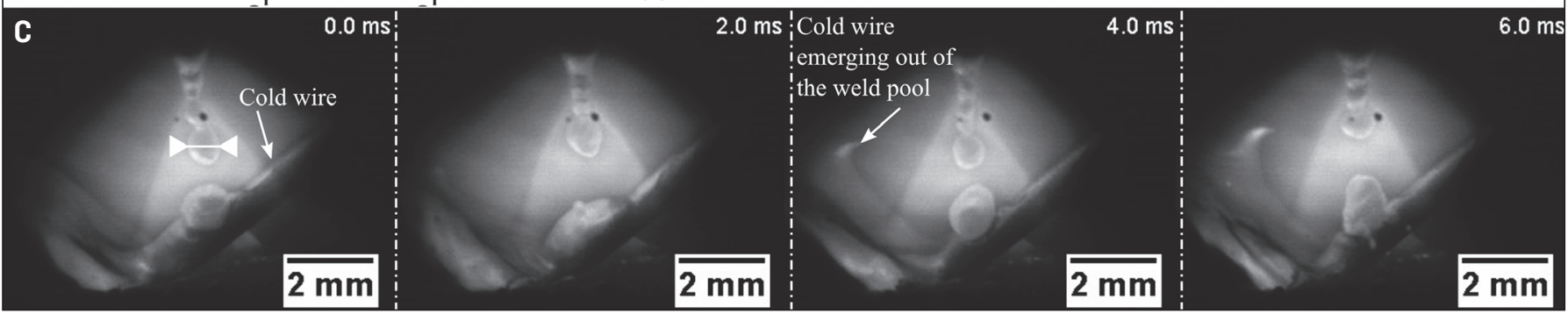

Fig. 4 - High-speed images of CW-GMAW-310 in./min-28 V-25 in./min-17 mm: A - 20\%; B - 80\%; C - 140\%.

Figure 8 shows the oscillograms for $350 \mathrm{in./min}$, which was a fully axial spray transfer mode. A cold wire feed rate of $80 \%$ could be accommodated by the energy supplied by the arc so no instability could be detected. In fact, it appeared the arc stabilized, because the spread of voltage and current were reduced.

It was also observed that increasing the cold wire feed rate to $140 \%$ did not cause instabilities - Fig. 8C. The transition current for spray in standard GMAW using $350 \mathrm{in} . / \mathrm{min}$ was 294.7 A (refer to Table 2).

\section{Cyclogrammes}

Cyclogrammes show the voltage plotted against the current to elucidate operational modes/points during welding operation. They can be used to determine process stability as well as transfer mechanism based on the shape of the cloud of points (Ref. 8). The experimental conditions employing 270 and 290 in./min, Fig. 9B and C, respectively, presented interchangeable metal transfer between spray and short circuit, which is consistent with the previous results. Once this range of 270-290 in./min was passed, the metal transfer across the arc moved toward spray, improving stabilization as indicated by the reduction of the area in the cyclogrammes for standard GMAW.

Figure 10 shows a cold wire feed rate of $80 \%$ stabilized the metal transfer, as indicated by the reduction of the cyclogramme area in comparison to standard GMAW - Fig. $10 \mathrm{~A}$. However, further increasing the cold wire fraction led to short circuits, which can be seen in Fig. 10C, where some points fall below $10 \mathrm{~V}$.

During unstable conditions, the cluster of the points increases, as a response of the power source feedback to stabilize the welding operation. However, certain points fall close to 10 $\mathrm{V}$, experiencing short circuit, as seen in Fig. 10C. This attempt to stabilize voltage/current response was caused by feedback in the welding source to maintain operation at a constant voltage (CV). This mechanism serves to keep the arc close to the set-point voltage and current through inductance control, which accounts for the current variation in time after a short circuit to reignite the arc. In fact, this cluster of points could become a supplementary indication of stability of a welding process parameter in addition to the sole area of the cyclogramme, which represents the total area formed by points in a cyclogramme irrespective of the cluster occurrence (Ref. 9).

Figure 11 shows cyclogrammes in the $330 \mathrm{in.} / \mathrm{min}$ condition. A $20 \%$ cold wire feed rate stabilized based on the reduced area of the cyclogramme, Fig. 11A, compared to Fig. $9 \mathrm{E}$. In contrast, the cold wire feed rate of $80 \%$ caused a small increase that can be considered within the stability limits Fig. 11B. However, at a $140 \%$ cold wire feed rate, the weld- 

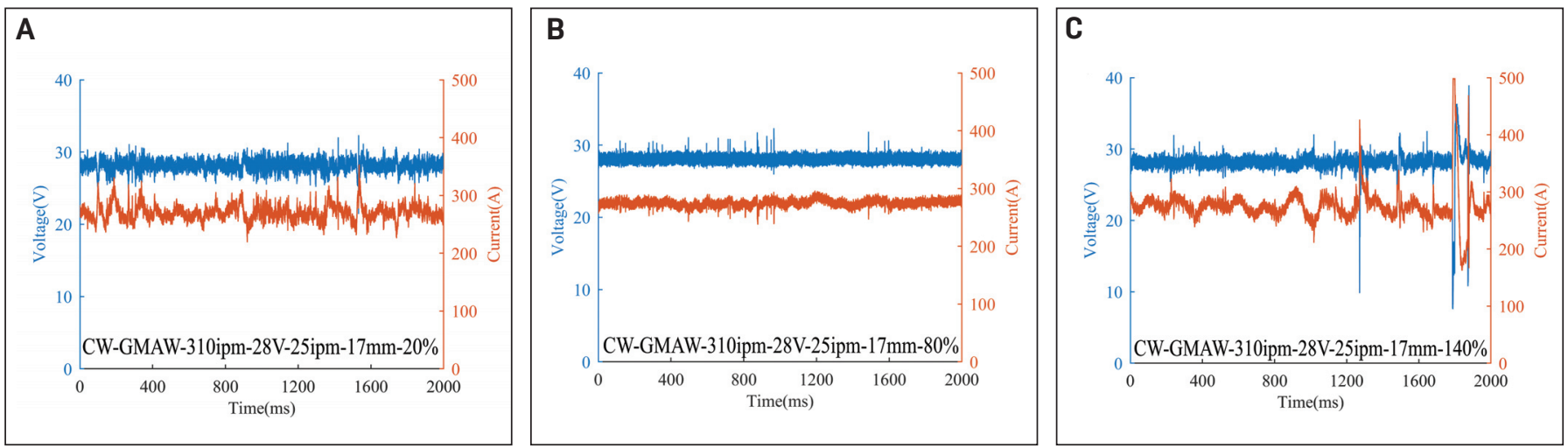

Fig. 5 - Oscillograms for CW-GMAW with WFS equal to 310 in./min with progressive values of cold wire feed rate: $A-20 \%$; $B-$ $80 \% ; C-140 \%$.
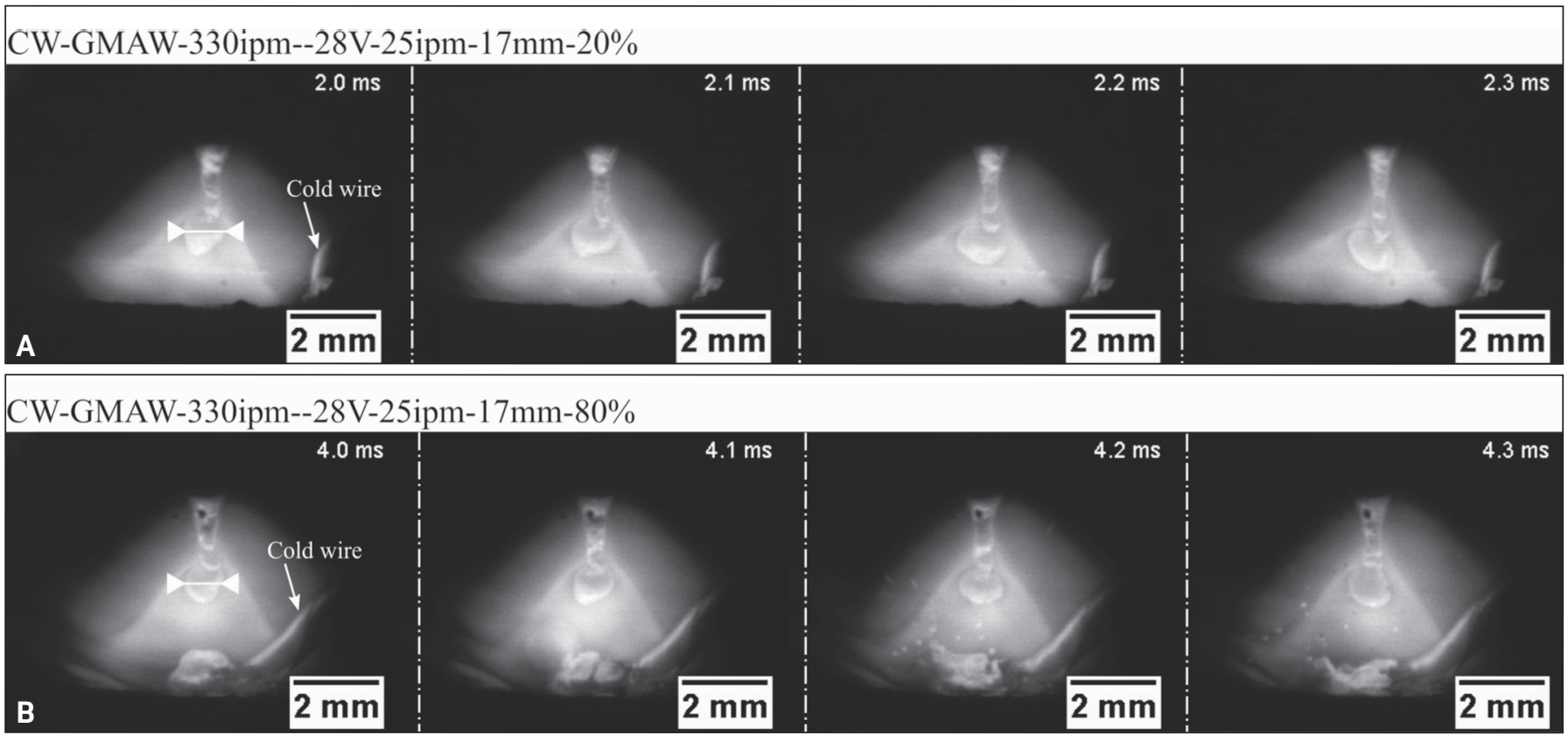

CW-GMAW-330ipm--28V-25ipm-17mm-140\%
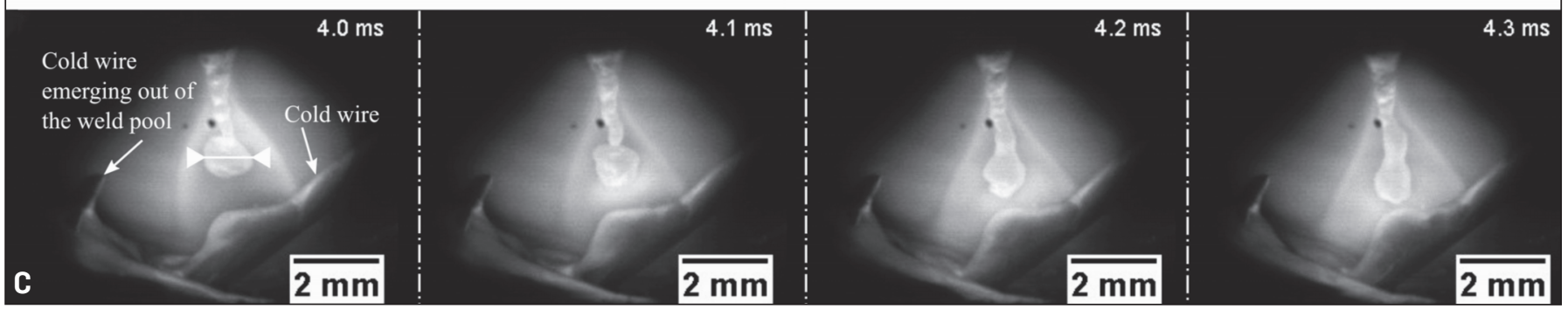

Fig. 6 - High-speed images of CW-GMAW-330 in./min-28 V-25 in./min-17 mm: A - 20\%; B - 80\%; C - 140\%.

ing stability was compromised by the short-circuit events, causing the cold wire contact with droplets still hanging on the electrode wire.

At a cold wire feed rate of $140 \%$, the cluster of points increases as a result of the power source feedback system, which attempts to stabilize the arc after short circuits. Figure 12 shows the cyclogrammes for the $350 \mathrm{in} . / \mathrm{min}$ condition, which corresponds to fully developed spray mode. When $20 \%$ cold wire feed rate was used, there was a reduction of the cyclogramme area, as seen by comparing Figs. 12A to 9E. The reduction of area is most pronounced when higher cold wire fractions were used, for instance, 80 and $140 \%$.

In contrast to the previous situations, the increase in the cluster of data points in Fig. 12 was not related to instabilities in the electric arc or short circuits caused by the cold wire emerging out of the weld pool. Rather, this was due to a higher 

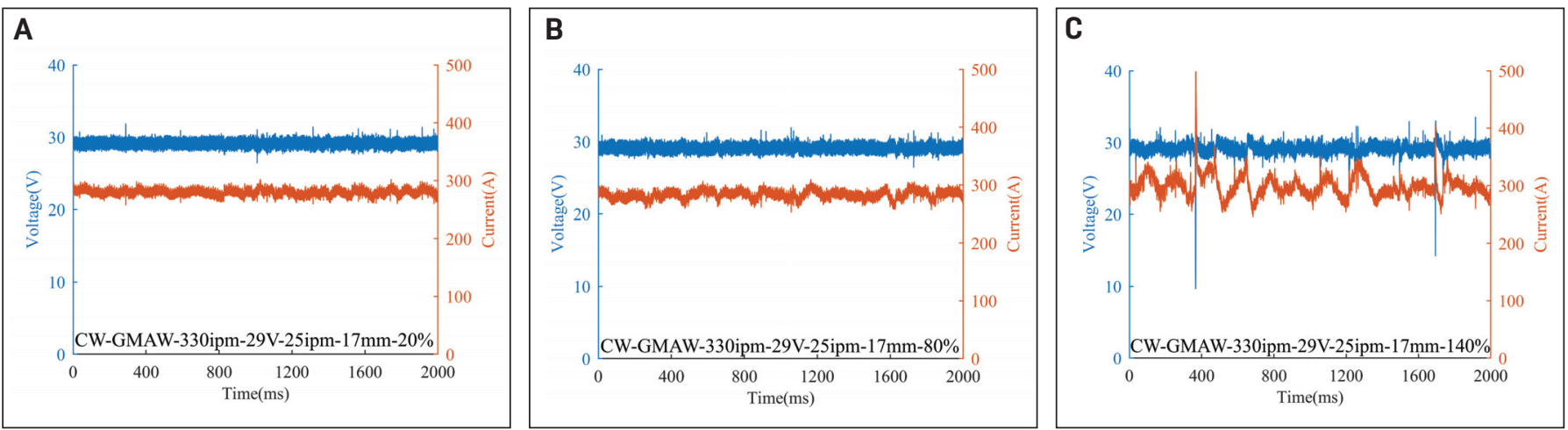

Fig. 7 - Oscillograms for CW-GMAW with WFS equal to $330 \mathrm{in./min}$ with progressive values of cold wire feed rate: $A-20 \%$; $B-$ $80 \% ; C-140 \%$.
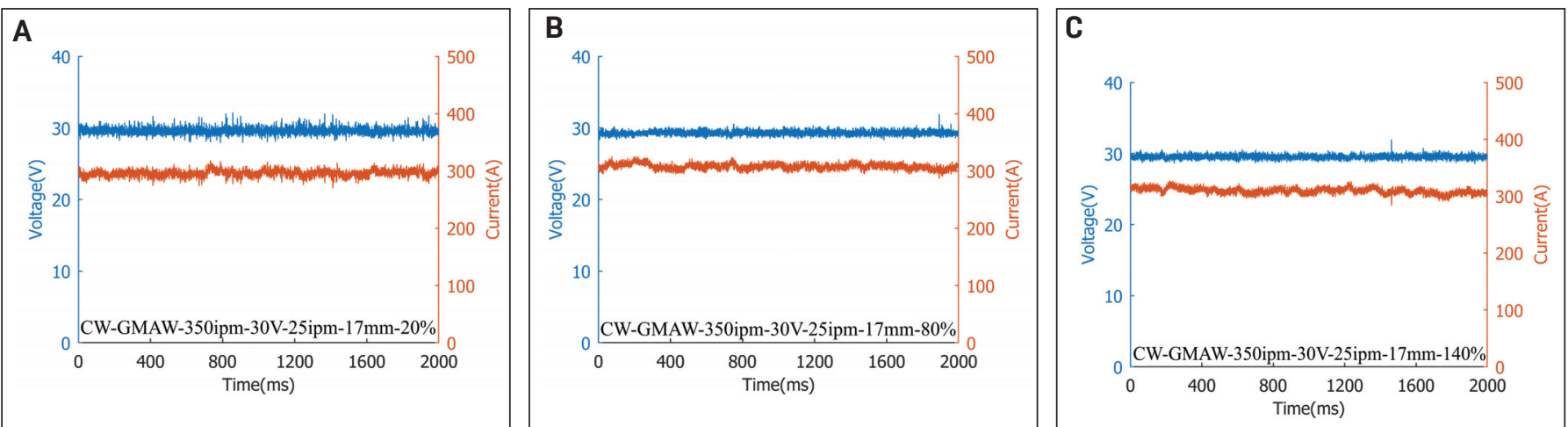

Fig. 8 - Oscillograms for CW-GMAW with WFS equal to 350 in./min with progressive values of cold wire feed rate: $A-20 \%$; $B-$ $80 \%$; C - $140 \%$.

stabilization of the welding process with the progressive stabilization of the arc due to arc pinning to the cold wire when the cold wire feed rates increased, and provided there was enough energy in the melt pool to sustain this extra wire.

\section{Droplet Frequency and Diameter}

The frequency of the droplets and their estimated diameter are presented in Fig. 13. Figure 13A and B show the droplet frequency for the $310 \mathrm{in} . / \mathrm{min}$ condition. Introducing the cold wire increased the droplet frequency. Though specifically for Fig.13A, the droplet frequency appeared unaltered in comparison to the standard GMAW, given the limits of variation represented by the confidence level at $95 \%$. The current for fully developed spray at $350 \mathrm{in./min}$ was $295 \mathrm{~A}$.

The increase in detachment frequency corresponded to a decrease in droplet diameter, which was caused by the increase in the tapering Lorentz force, which varied directly with the current (Ref. 10). Figure 13B shows the trend in droplet detachment frequency (Fig. 13A) was maintained with the droplet starting to transit to a spray condition at $80 \%$ cold wire feed rate. This was due to the increase in current to melt the extra wire introduced in the arc. At a cold wire feed rate of $80 \%$, the transition to spray occurred in a much lower current than the fully spray condition as reported in the metal transfer dynamics section.

Figure $13 C$ and D show the droplet frequency and the droplet diameter for $330 \mathrm{in} . / \mathrm{min}$, respectively. Similar to the case described in the previous paragraph, the transition for spray started at $80 \%$ cold wire feed rate, in which the error bars indicate the droplet frequency was higher than the droplet frequency of reference. Using a WFS value of 330 $\mathrm{in./min}$, the transition to spray was more gradual than when using a WFS of $310 \mathrm{in.} / \mathrm{min}$. Similarly, the transition to spray started at the cold wire feed rate of $80 \%$ when compared to the reference level - see Fig. $13 C$ and D. The reason for the difference in slope behavior of these two cases remains unclear and is worthy of future study.

\section{Average Resistance of the Arc Plasma}

Figure 14 presents the arc resistance for the welds using 310, 330, and $350 \mathrm{in./min}$ wire feed speed. The arc resistance was estimated using Equation 2 as described in the methodology. Valensi et al. (Ref. 11 ) reported in the transition from globular to spray, the conductivity of the plasma column increased due to the metal vapor generation rate increase. The resistance of the plasma column in a fully developed spray condition (350 in./min) is equal to $0.1028 \Omega-$ Fig. 14C. Comparing the resistance for the conditions of 310 and $330 \mathrm{in./min}$ to this standard value, the resistance limit to allow a fully spray transfer for the conditions was mapped out in this work. According to Fig. 14A, the resistance for $80 \%$ was $0.1025 \Omega$, which is lower than the reported value for spray using $350 \mathrm{in} . / \mathrm{min}$. Also, according to Fig. 14B, the resistance for an $80 \%$ feed rate was $0.1030 \Omega$, which was close to the value reported in Fig. 14A. This indicates the results of arc resistance were consistent with the droplet fre- 


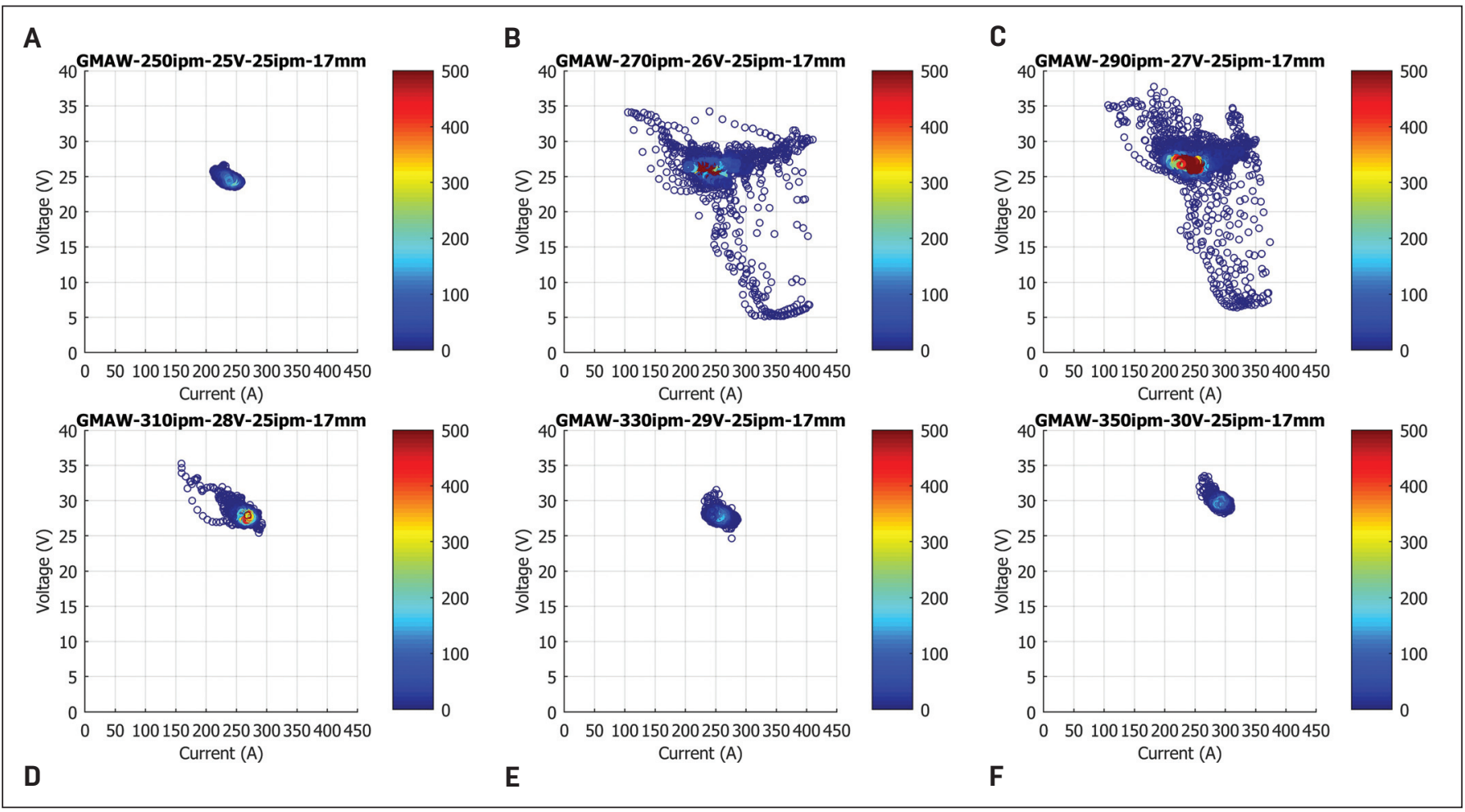

Fig. $9-$ Cyclogrammes for standard GMAW conditions: $A-250 \mathrm{in.} / \mathrm{min} ; B-270 \mathrm{in} . / \mathrm{min} ; \mathrm{C}-290 \mathrm{in} . / \mathrm{min} ; \mathrm{D}-310 \mathrm{in} . / \mathrm{min} ; E-330$ in./min; F-350 in./min. Color bar indicates density of data.

quency measurements. For the CW-GMAW conditions in which the WFS was 310 and $330 \mathrm{in./min}$, the transition to spray suddenly occured at an $80 \%$ cold wire feed rate, with arc current values of 274.42 and $283.01 \mathrm{~A}$, respectively (Table 3). These currents are inferior to the average current of 294.65 A, reported in Table 2, for a fully spray regime transfer in standard GMAW.

The size of the variation around the average arc resistance at $140 \%$ in Fig. 14A and B was due to the short circuit (disturbances) caused by the excessive amount of cold wire in the arc. The arc resistance plots indicate that increasing the cold wire fraction led to pinning of the electric arc to the cold wire for high cold wire fractions (>100\%), provided there was enough energy to accommodate this high cold wire fraction. When there was enough energy to accommodate the cold wire (350 in./min), the resistance variation was lower than in the standard GMAW for 80 and 140\% cold wire feed rates - Fig. 14C. The decrease of the resistance indicated an improvement in arc conductivity, which accounted for stability and an increase in current, leading to higher values of detachment force from the self-induced magnetic field.

\section{Discussions}

\section{Metal Transfer and Globular-to-Spray Transfer Mechanism in CW-GMAW}

There are basically two theories that try to explain the phenomena of metal transfer in welding: The static balance force theory (SBFT) by Waszink and Graat (Ref. 12) and the pinch instability theory (PIT) proposed by Allum (Refs. 13,
14). The SBFT accurately predicts the droplet diameter in globular transfer mode while the PIT performs better in spray transfer. However, neither can predict the globular-tospray transfer. Recently, Zhao and Chung (Ref. 15) reported the phase field method can approximate the globular-tospray transition current, along with the droplet sizes in the transition regime.

During metal transfer, the droplets are subjected to three forces: electromagnetic force $\left(F_{e m}\right)$; gravitational force $\left(F_{g}\right)$; and surface tension force $\left(F_{s}\right)$. In this analysis, the viscous drag force of the plasma and the arc pressure are disregarded because they account for only $10 \%$ of $F_{s}$, according to Waszink and Graat (Ref. 12). In globular transfer, droplet detachment is governed by $F_{g}$ because the droplet diameter is large, while in spray mode, detachment is governed by the electromagnetic force.

The mechanism of hastening the onset of the globular-tospray transfer in CW-GMAW is related to the current increase caused by higher total wire feed (both electrode and cold wire feed rate) applied in CW-GMAW. This mechanism is similar to the one proposed by Kim and Eagar (Ref. 10). The total power delivered to the anode $\left(\dot{Q}_{\text {total }}\right)$ can be written as follows:

$$
\dot{Q}_{\text {total }}=\left(3 / 2 k T / e+V_{a}+\phi\right) I+\left(\bar{\rho} L / A I^{2}\right)
$$

where $k$ is the Boltzmann constant, $T$ is the electron temperature, $e$ is the electron charge, $V_{a}$ is the anode voltage drop, $\phi$ is the work function of the electrode material, $\bar{\rho}$ is the average resistivity of the electrode material, $L$ is the electrode extension, $A$ is the cross-sectional area of the electrode, and $I$ is the welding current. The first parenthesis is the power imparted by the electron condensation, while the second 


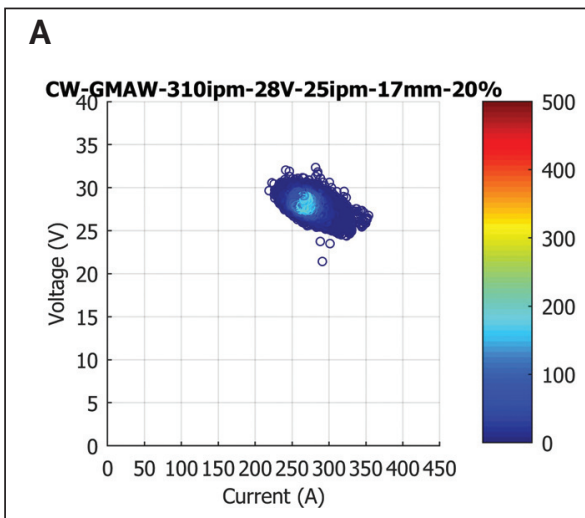

B

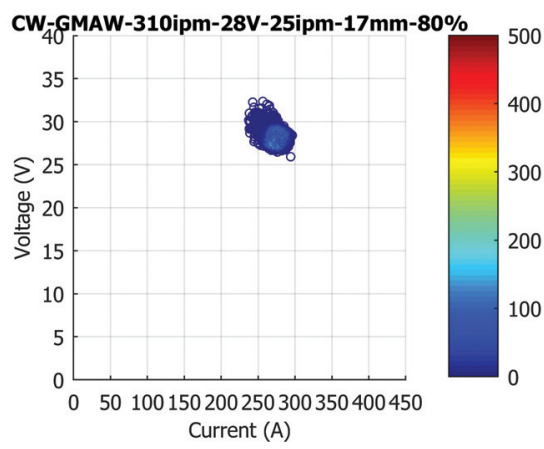

C

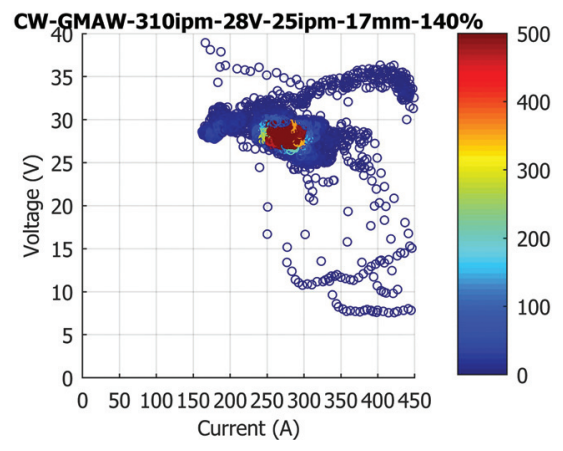

Fig. $10-$ Cyclogrammes for CW-GMAW conditions using WFS = 310 in./min: A $-C W-20 \% ; B-C W-80 \% ; C-C W-140 \%$. Color bar indicates density of data points.

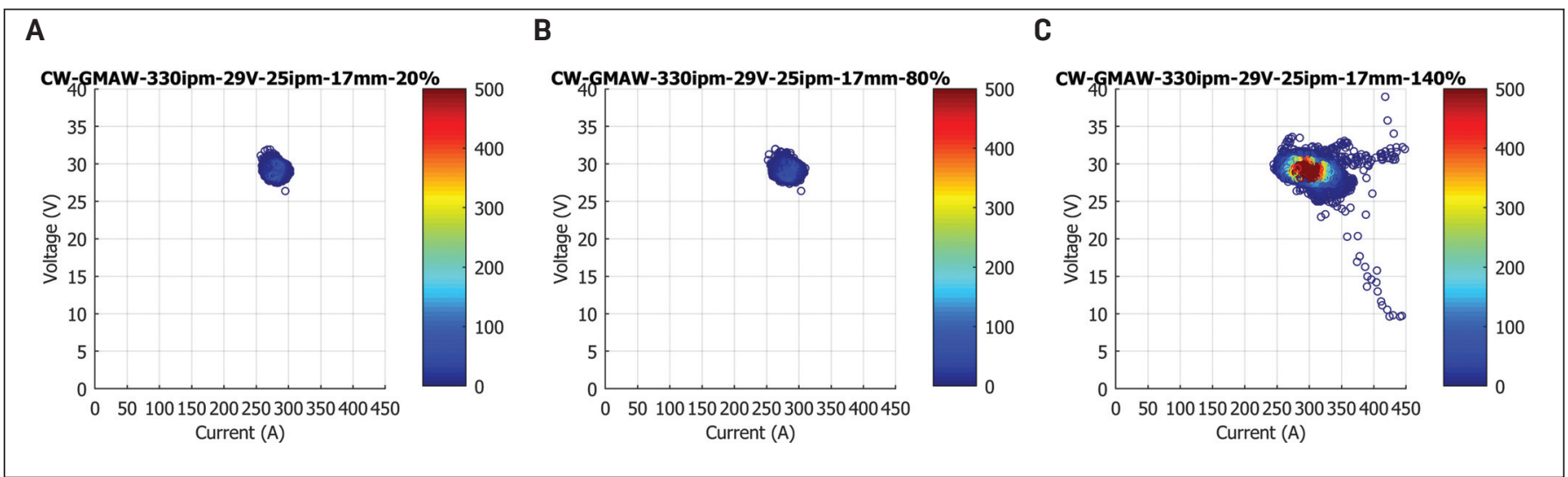

Fig. $11-$ Cyclogrammes for CW-GMAW conditions using WFS = 330 in./min: A - CW-20\%; B - CW-80\%; C - CW-140\%. Color bar indicates density of data points.

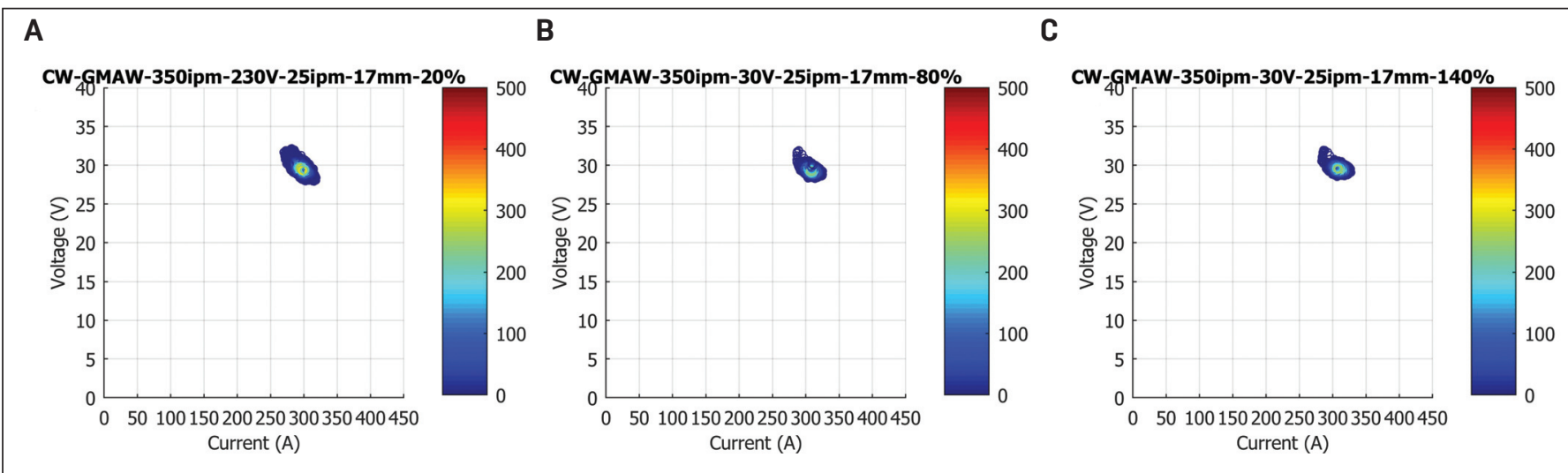

Fig. 12 - Cyclogrammes for CW-GMAW conditions using WFS = 350 in./min: $A-C W-20 \%$; B $-C W-80 \%$; C - CW-140\%. Color bar indicates density of data points.

parenthesis is the power due to Joule effect. The total wire feed in CW-GMAW causes the Joule power to increase, acting similar to an increase in electrode extension. Thus, the electrode melting occurs at reduced arc currents in CWGMAW compared to standard GMAW, leading to electrode tapering at lower currents compared to standard GMAW. From the SBFT theory, the only holding force in the electrode droplet is the surface tension $\left(F_{s}\right)$, which is as follows:

$$
F_{s}=\pi d_{e} \gamma
$$

where $d_{e}$ is the electrode diameter and $\gamma$ is the surface tension coefficient of the molten electrode. Thus, as tapering of the electrode proceeds, $d_{e}$ decreases and, consequently, $F_{s}$ decreases as well, which cause smaller droplets to be formed, accounting for the sooner globular-to-spray transition in CW-GMAW. 


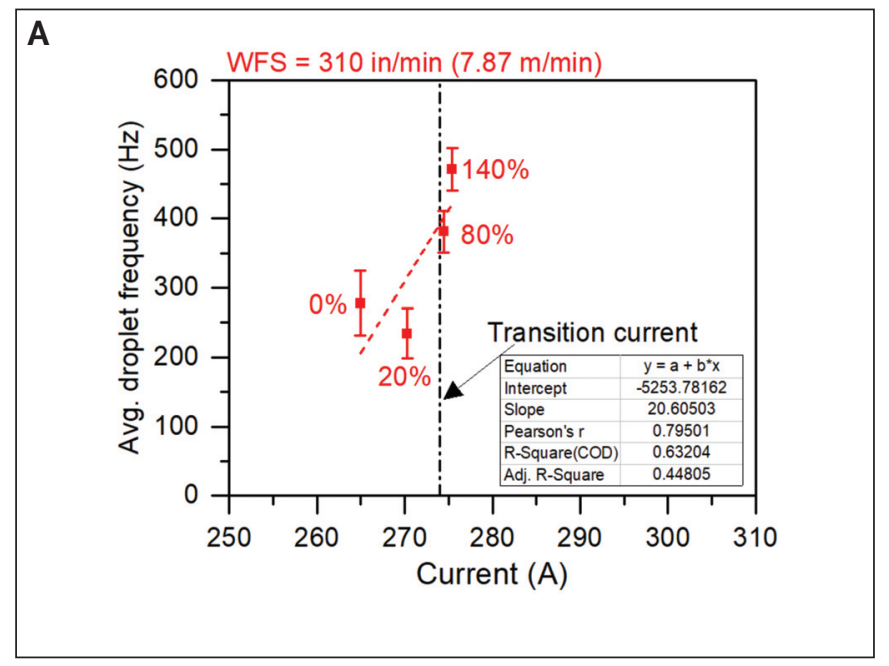

C

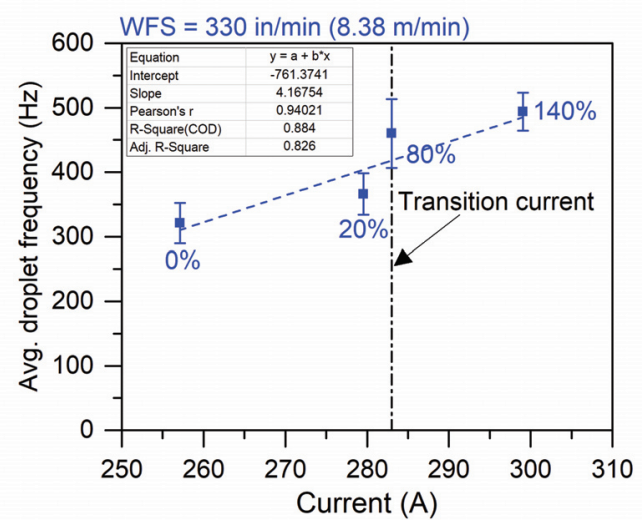

B

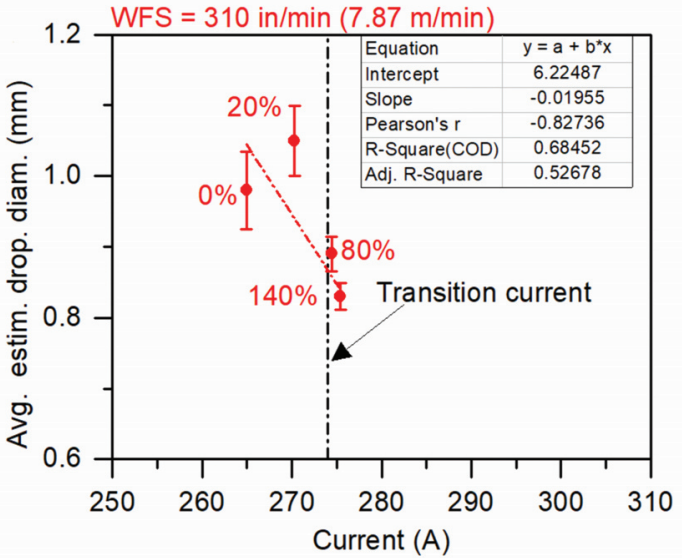

D

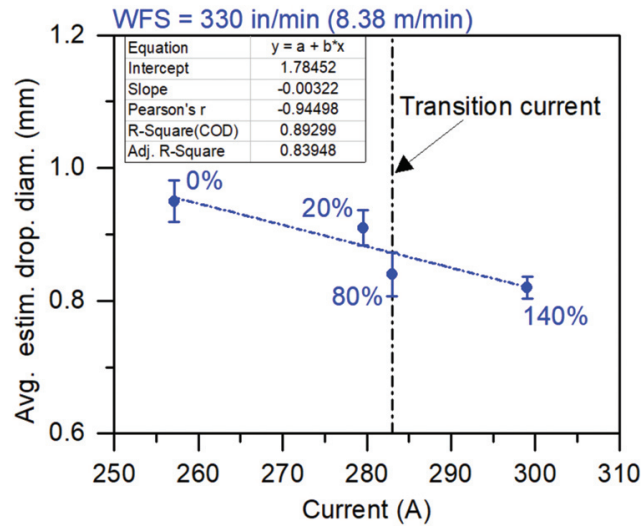

Fig. 13 - Average droplet frequency and estimated average droplet diameter: A - Average droplet frequency for WFS of 310 in./min; B - average droplet diameter for WFS of $310 \mathrm{in./min;} \mathrm{C} \mathrm{-} \mathrm{average} \mathrm{droplet} \mathrm{frequency} \mathrm{for} \mathrm{WFS} \mathrm{of} 330 \mathrm{in}$./min; D - average droplet frequency for WFS of $330 \mathrm{in}$./min. The percentages in the graph indicate the cold wire feed rate. Standard GMAW is to 0\% cold wire feed rates.

\section{Arc Stability and Arc Resistance}

The methodology proposed to assess arc stability using the cyclogrammes in the results section uses the following: 1) the area of the cyclogramme and 2) the cluster of points in the cyclogramme. These two features are complementary in the sense that when the welding operation is stable, the area of the cyclogramme decreases along with the cluster of points see Fig. 9A, E, and F for standard GMAW. When the cold wire feed rate reaches $80 \%$, the stability in CW-GMAW is comparable to the standard GMAW - Figs. 11B, 12B. The increase in cluster of points, observed for instance in Figs. $10 \mathrm{C}$ and $11 \mathrm{C}$, is caused by the feedback mechanism in the welding power source to maintain the instantaneous voltage/current near the values of current and voltage set before the welding operation.

The transition to spray transfer is accompanied by a reduction in resistance (increase of conductivity) of the arc column, as shown in Fig. 14. This mechanism is likely due to higher ionization caused by the increase in metal vapor (from electrode and cold wire derived). Lancaster (Ref. 16) reported that in iron or steel arcs, the ionization is due to small amounts of metal vapor originating from the electrode. The introduction of cold wire causes a reduction in CTWD resistance, which is the sum of electrode extension resistance and arc resistance (Ref. 17). This decrease in arc resistance likely facilitates the flow of charge inside the arc. This facilitation in current flow likely increases the current density, which might explain why the electromagnetic force becomes increasingly dominant with additional cold wire feed rates (Ref. 18).

\section{Conclusions}

Standard and cold wire GMAW welds at constant voltage were performed to identify the current at which the transfer mode transitions from globular to spray regime. The transition to spray was studied using high-speed imaging and high frequency of sampling electrical signals. The following conclusions were reached:

1. The transition from globular to spray in cold wire GMAW occurs at 4 to $7 \%$ lower current level when compared to standard GMAW for the same process parameters;

2. The transition from globular to spray occurs due to an increase in current with the increase of cold wire feed rates, which leads to an increase in tapering of the electrode by elec- 

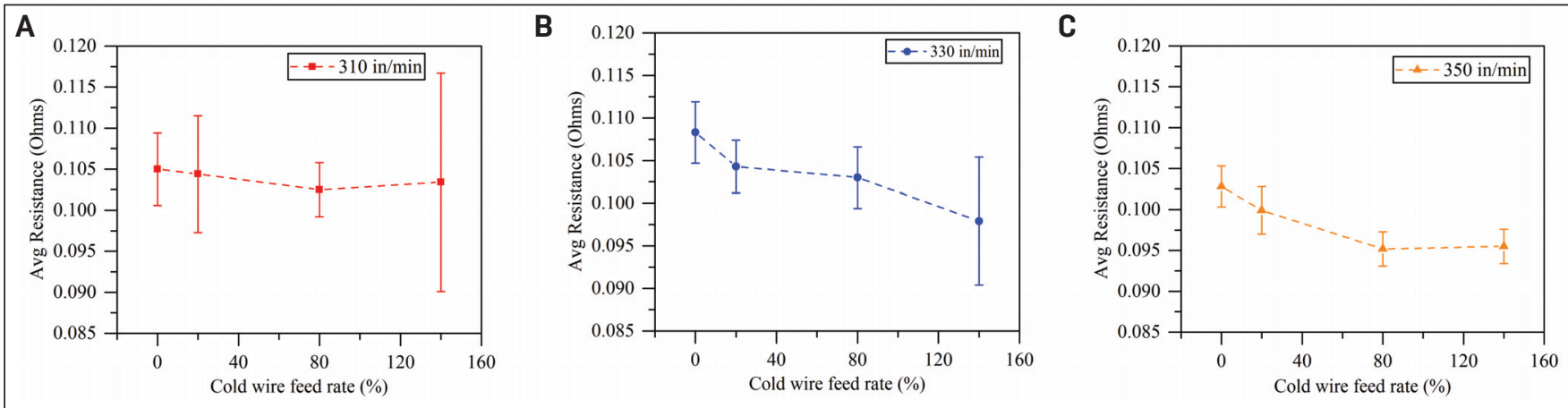

Fig. 14 - Arc resistance values based on instantaneous values of current and voltage for three distinct WFS conditions: $A-310$ in./min; B - 330 in./min; $C-350$ in./min. Error bars show $95 \%$ confidence intervals.

tron condensation, which reduces the surface tension force (only droplet holding force); and

3. The resistance of the arc plasma column seems to decrease with the increase of cold wire feed rates, which accounts for an increase in current. This is probably due to higher metal vapor fraction generated by the cold wire.

\section{Acknowledgments}

The authors would like to acknowledge Natural Sciences and Engineering Research Council of Canada (NSERC) and TransCanada Energy (TCE) for financial support of this project. They would like to also acknowledge the Centre for Advanced Materials Joining (CAMJ) of the University of Waterloo, where all the experiments were performed. Lastly, P. D. C. Assunção would like to thank the Coordination for the Improvement of Higher Education Personnel (CAPES) of the Brazilian Ministry of Education for the scholarship to visit the University of Waterloo.

\section{References}

1. Lowke, J. J. 2009. Physical basis for the transition from globular to spray modes in gas metal arc welding. Journal of Physics D: Applied Physics 42: 135204. DOI: 10.1088/0022-3727/42/13/ 135204

2. Lowke, J. J. 2011. Globular and spray transfer in MIG welding. Weld World 55: 19-23.

3. Methong, T., Shigeta, M., Tanaka, M. et al. 2018. Visualization of gas metal arc welding on globular to spray transition current. Science and Technology of Welding and Joining 23: 87-94. DOI: 10.1080/13621718.2017.1344454

4. Ribeiro, R. A., Dos Santos, E. B. F., Assunção, P. D. C. et al. 2019. Cold wire gas metal arc welding: Droplet transfer and geometry. Welding Journal 98(5): 135-s to 149-s. DOI: 10.29391/2019.98.011

5. Ribeiro, R. A., Assunção, P. D. C., Dos Santos, E. B. F. et al. 2019. Application of cold wire gas metal arc welding for narrow gap welding (NGW) of high strength low alloy steel. Materials (Basel): 12. DOI: $10.3390 / \mathrm{ma} 12030335$

6. Soderstrom, E. J., and Mendez, P. F. 2008. Metal transfer during GMAW with thin electrodes and $\mathrm{Ar}-\mathrm{CO}_{2}$ shielding gas mixtures. Welding Journal 87(5): 124-s to 133-s.
7. Scotti, A., Ponomarev, V., and Lucas, W. 2014. Interchangeable metal transfer phenomenon in GMA welding: Features, mechanisms, classification. Journal of Materials Processing Technology 214: 24882496. DOI: 10.1016/j.jmatprotec.2014.05.022

8. Jorge, V. L., Gohrs, R, and Scotti, A. 2017. Active power measurement in arc welding and its role in heat transfer to the plate. Weld World 61: 847-856. DOI: 10.1007/s40194-017-0470-9

9. Suban, M., and Tušek, J. 2003. Methods for the determination of arc stability. Journal of Materials Processing Technology 143-144: 430-437. DOI: 10.1016/S0924-0136(03)00416-3

10. Kim, Y.-S., and Eagar, T. W. 1993. Analysis of metal transfer in gas metal arc welding. Welding Journal 72(6): 269-s to 278-s.

11. Valensi, F., Pellerin, S., Castillon, Q. et al. 2013. Study of the spray to globular transition in gas metal arc welding: A spectroscopic investigation. Journal of Physics D: Applied Physics 46. DOI: 10.1088/0022-3727/46/22/224005

12. Waszink, J. H., and Graat, J. H. 1983. Experimental investigation of the forces acting on a drop of weld metal. Welding Journal 62(4): 108-s to 116 -s.

13. Allum, C. J. 1985. Metal transfer in arc welding as a varicose instability. I. Varicose instabilities in a current-carrying liquid cylinder with surface charge. Journal of Physics D: Applied Physics 18: 14311446. DOI: $10.1088 / 0022-3727 / 18 / 7 / 029$

14. Allum, C. J. 1985. Metal transfer in arc welding as a varicose instability. II. Development of model for arc welding. Journal of Physics D: Applied Physics 18: 1447-1468. DOI: 10.1088/00223727/18/7/030

15. Zhao, Y., and Chung, H. 2018. Numerical simulation of the transition of metal transfer from globular to spray mode in gas metal arc welding using phase field method. Journal of Materials Processing Technology 251: 251-261. DOI: 10.1016/j.jmatprotec.2017.08.036

16. Lancaster, J. F., ed. 1986. The Physics of Welding, $2^{\text {nd }}$ ed. Pergamon Press, Exeter.

17. Smartt, H., and Einerson, C. 1993. A model for heat and mass input control in GMAW. Welding Journal 72(5): 217-s to 229-s.

18. Choi, S. K., Yoo, C. D., and Kim, Y. S. 1998. Dynamic simulation of metal transfer in GMAW, Part 1: Globular and spray transfer modes. Welding Journal 77(1): 38-s to 44-s.

R. A. RIBEIRO (rdearauj@uwaterloo.ca) and A. P. GERLICH are with the Centre for Advanced Materials Joining (CAMJ), University of Waterloo, Waterloo, Ontario, Canada. P. D. C. ASSUNÇÃO and E. M. BRAGA are with the Metallic Materials Characterization Laboratory (LCAM), Federal University of Pará (UFPA), Belém - PA, Brazil. E. B. F. DOS SANTOS is with Liburdi Automation Inc. 